\title{
Study of maximum power point tracking based on impedance module analysis method for grid-connected PV generation system
}

\author{
Ning $\mathrm{An}^{1 . a}$, Baochun $\mathrm{Lu}^{1}$, Baoguo $\mathrm{Li}^{1}$, Zhonglin $\mathrm{Zhang}^{2}$, Tao Wang ${ }^{2}$ and Hong Bai ${ }^{2}$ \\ ${ }^{1}$ Department of Electrical Engineering Liaoning University of Technology, No. 169, Shiying Street, Guta District, \\ Jinzhou, 121001, P. R. China \\ ${ }^{2}$ Jinzhou City Power Supply Company State Grid Liaoning Electric Power Co. Ltd. No. 20, Jiefang Street, Guta \\ District, Jinzhou 121000, P.R. China
}

\begin{abstract}
In this paper, a new method of maximum power point tracking(MPPT) based on impedance module analysis is presented in two-stage three-phase grid-connected PV system. The method can obtain maximum power from PV array by adjusting duty cycle of DC Boost converter based on taking advantage of internal resistance variation of PV array. Simplified equivalent model of the system is established to obtain maximum power. By means of impedance module analysis method, power transmission formula via duty cycle and equivalent resistance is derived, which is influenced by duty cycle and output voltage of PV array, and the maximum power transmission condition is given. Simulation results show that the proposed method can obtain the maximum power. Meanwhile, the correctness of proposed method is verified.
\end{abstract}

Keywords: impedance module; grid-connected PV generation system; MPPT; duty cycle.

\section{Introduction}

With the crisis of energy and the serious pollution, importance of solar energy is also becoming increasingly apparent. Grid-connected PV generation system makes it possible to make widely use of solar energy, so it becomes a hot topic of research. Power Point Tracking Maximum (MPPT) in gridconnected inverter control is the key to PV generation system.

It is necessary to make full use of the power generation efficiency of PV cell because of high cost of PV generation system. This makes MPPT become an indispensable control strategy for the system. Currently, control method of maximum power point tracking in PV generation system mainly includes Perturb \& Observe (P\&O) method and increment conductance (INC) algorithm. Although P\&O method has simple structure and less measured parameters, there are problems in fluctuations of output power near maximum power point. If step length is too large, then fluctuations will increase, otherwise, PV cell is likely to work in low voltage area for a long time. However variable step length can improve stability of system, it is impossible to achieve the best dynamic performance in theory [1]. Even though INC algorithm is better than P\&O method when external environment changes rapidly,

\footnotetext{
a Corresponding author : anning_0823@163.com
} 
there is still a problem in step length selecting. In addition, there are constant voltage method, constant current method and neural network method and so on [2, 3].

This paper puts forward a new idea of MPPT strategy based on analysis method of impedance module. Not only the idea includes PV array and DC-DC converter, but also the whole grid-connected PV system.

\section{Main idea of MPPT based on impedance module}

Analysis method of impedance module originates from the maximum power transfer theorem. P-V curve as shown in Figure 1 (a) based on circuit in Figure 1 (b) indicates that the condition which load obtains maximum power $\mathrm{P}_{\mathrm{m}}$ is that impedance module of load impedance conjugate matches internal impedance when load impedance angle $\varphi_{\mathrm{eq}}$ is constant. For power system such as Figure 1 (b) shows, when impedance module of load $Z_{\mathrm{eq}}$ less than that of $\mathrm{Z}_{\mathrm{in}}$ corresponding the upper half of P-V curve, output power increases with impedance module of $Z_{\text {eq }}$ increase. When impedance module of load $Z_{\text {eq }}$ greater than that of $Z_{\text {in }}$ corresponding the lower half of $P-V$ curve, output power decreases with impedance module of $\mathrm{Z}_{\text {eq }}$ increase. When impedance module of load $\mathrm{Z}_{\text {eq }}$ equals to that of $\mathrm{Z}_{\text {in }}$ corresponding the peak of $\mathrm{P}-\mathrm{V}$ curve, output power is maximum [4].

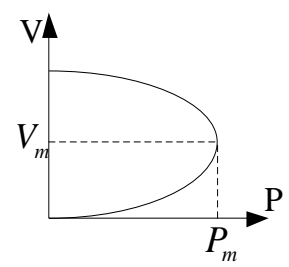

(a)

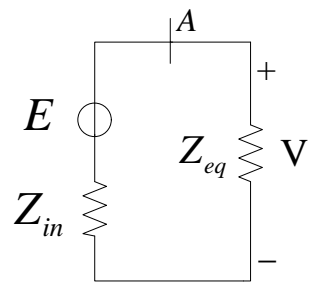

(b)

Figure 1. P-V curve and equivalent circuit model of simple power system

Aiming the topology structure for two-stage three-phase grid-connected PV system as shown in Figure 2, integral equivalent model simulated by Matlab/Simulink containing PV array, boost converter, inverter, filter circuit and grid voltage $e_{k}(k=1,2,3)$ has been established.

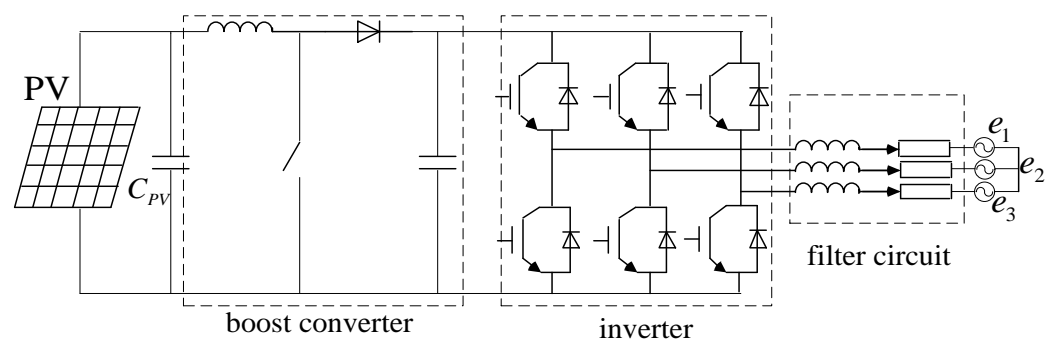

Figure 2. Two-stage three-phase grid-connected PV system

\section{Equivalent modeling of grid-connected PV generation system}

\subsection{Modeling and variation of PV cell}

PV cell equivalent circuit is shown in Figure 3. 


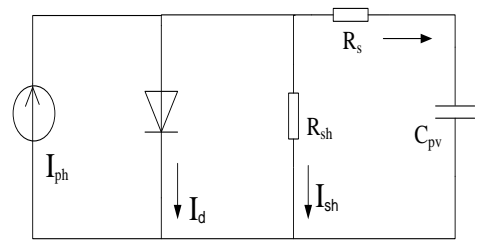

Figure 3. Equivalent circuit of PV cell

$$
I=I_{p h}-I_{d}-I_{s h}=I_{p h}-I_{0}\left\{\exp \left[\frac{q\left(U_{d c}+I R_{s}\right)}{A K T}-1\right]\right\}-\frac{U_{d c}+I R_{s}}{R_{s h}}
$$

Where $\mathrm{K}$ is Boltzmann constant $\left(1.38 \times 10^{-23} \mathrm{~J} / \mathrm{K}\right)$, A is ideality factor of PN junction, $\mathrm{q}$ is electric charge $\left(1.6 \times 10^{-19} \mathrm{C}\right)$, $T$ is the operating temperature, $I_{p h}$ is photo-current, $I_{d}$ is diode current, $I_{0}$ is invert saturation current of $\mathrm{PN}$ junction, $\mathrm{R}_{\mathrm{s}}$ represents series resistance, $\mathrm{R}_{\mathrm{sh}}$ represents parallel resistance [5].

As shown in Figure 4, under the XJCM-SIMULATOR test platform and 25 degrees Celsius condition, it can be concluded that internal resistance of PV cell at maximum power point is decreased with light intensity increase ranges from $700 \mathrm{~W} / \mathrm{m}^{2}$ to $1200 \mathrm{~W} / \mathrm{m}^{2}$ as shown in Figure 4(a). And internal resistance of PV cell tends to be constant in the same light intensity and temperature condition as is shown in Figure 4(b).

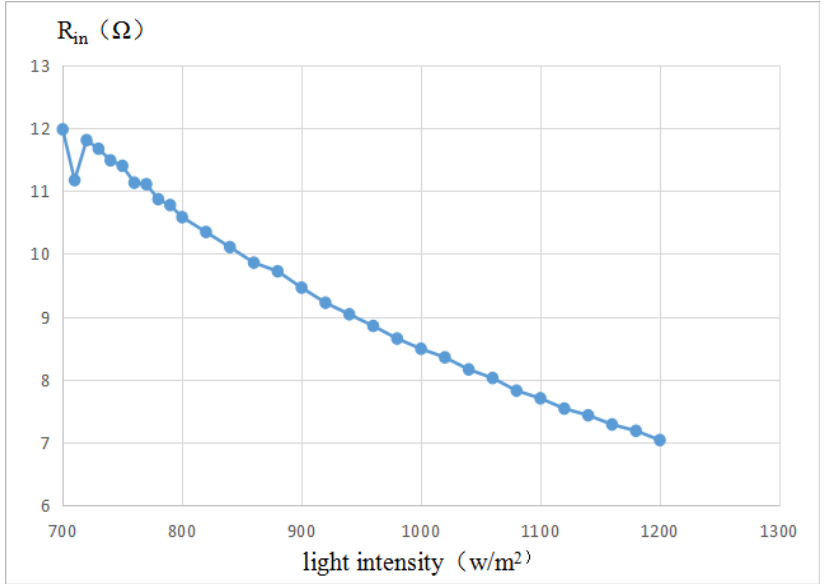

(a)

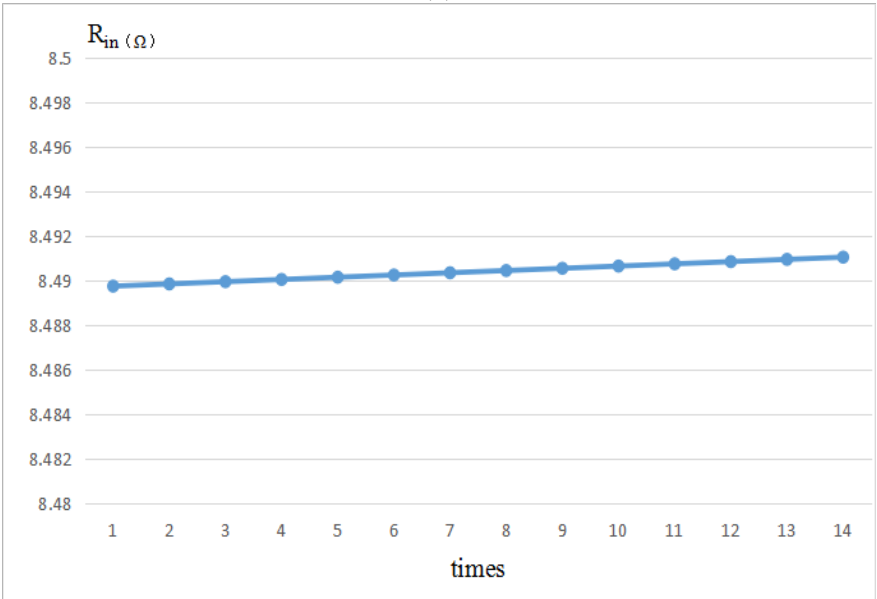

(b)

Figure 4. Variations of resistance 


\subsection{Modeling of DC-DC converter}

DC-DC converter uses a switching signal according to error signal and generated by a control circuit to control conduction and cutoff of switch transistors $\mathrm{S}$ and stabilizes voltage by energy storage and release of inductor $\mathrm{L}_{1}$, capacitor $\mathrm{C}$ and diode D. This paper adopts Boost circuit as shown in Figure 5.

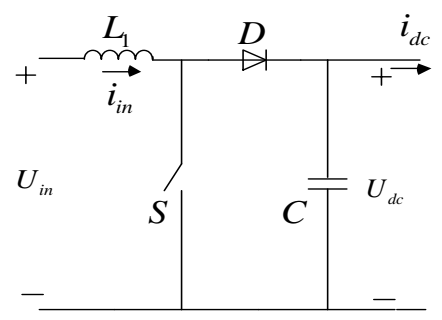

Figure 5. Boost circuit

Output voltage is

$$
U_{d c}=\frac{T_{s}}{t_{\text {off }}} U_{\text {in }}-U_{D}-\frac{t_{\text {on }}}{t_{\text {off }}} U_{\text {sat }}
$$

Signal time is $T_{\mathrm{s}} . \mathrm{T}_{\mathrm{s}}=\mathrm{T}_{\text {on }}+\mathrm{T}_{\text {off. }}$. Under ideal condition: $\mathrm{U}_{\mathrm{sat}} \approx \mathrm{U}_{\mathrm{D}} \approx 0$. Equation (2) shows that output voltage $U_{\mathrm{dc}}$ is proportional to duty cycle $\mathrm{D}$ and is always higher than input voltage $U_{\text {in }}[6]$. Boost circuit does not consume electric energy if loss in circuit is ignored, which means that it can be regarded as DC-DC transformer [7].

\subsection{Modeling of inverter DC side.}

According to unity of topology structure between inverter and 4 quadrant converter(PWM reversible rectifier), state space average (SSA) model of 4 quadrant converter can be applied to SSA model of inverter, and then equivalent mathematical model and approximate simplified equivalent model of inverter DC side are presented.

Equations should be centred and should be numbered with the number on the right-hand side.

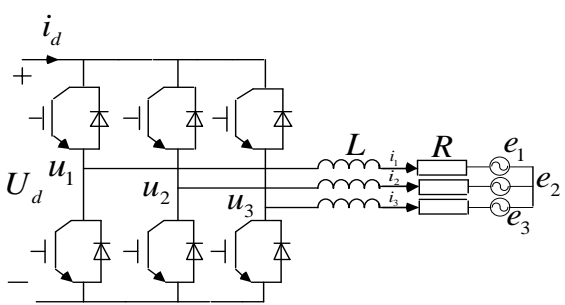

(a)

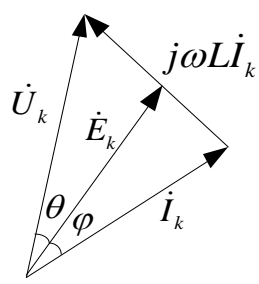

(b)

Figure 6. Equivalent circuit model and phasor plot of inverter

Figure 6(a) shows that circuit model of PWM inverter, filter inductor L and resistance R. In addition, $\mathrm{u}_{\mathrm{k}}$ and $\mathrm{i}_{\mathrm{k}}(\mathrm{k}=1,2,3)$ represent output voltage and current of inverter. Phase difference between $\mathrm{e}_{\mathrm{k}}$ and $\mathrm{i}_{\mathrm{k}}$ is $\varphi$. Supporting capacity of DC side is merged into Boost circuit. According to the basic circuit relationship in Figure 6(a), we can get

$$
L \dot{i}+i_{k} R=\left(d_{k}-d_{M}\right) u_{d}-e_{k} \quad(k=1,2,3)
$$

Suppose that input voltage of DC side is $u_{d}$, upper switch duty cycle of the k phase is $d_{k}$ and average duty cycle of three phase is 


$$
d_{M}=\frac{1}{3} \sum_{k=1}^{3} d_{k}=\frac{1}{2}
$$

In order to obtain input current $i_{d}$ and resistance function of inverter DC side $R_{d}$, suppose that

$$
\left\{\begin{array}{l}
e_{k}=E \sin \left[\omega t-(k-1) 120^{\circ}\right] \\
d_{k}=\frac{1}{2}+\frac{m}{2} \sin \left[\omega t-(k-1) 120^{\circ}+\theta\right] \\
\alpha_{k}=\omega t-(k-1) 120^{\circ} \quad(k=1,2,3)
\end{array}\right.
$$

Combining (3) and (5) ,we can get

$$
L \dot{i}+i_{k} R=\frac{m u_{d}}{2} \sin \left(\alpha_{k}+\theta\right)-E \sin \alpha_{k} \quad(k=1,2,3)
$$

where

$$
\left\{\begin{array}{l}
u_{k}=\frac{m u_{d}}{2} \sin \left(\alpha_{k}+\theta\right) \\
U_{k}=\frac{m u_{d}}{2}(k=1,2,3)
\end{array}\right.
$$

Suppose steady state solution of (6) and vector parameter are

$$
\begin{gathered}
i_{k p}=I \sin \left(\alpha_{k}-\phi\right) \quad(k=1,2,3) \\
\left\{\begin{array}{l}
I=\sqrt{\frac{U_{k}^{2}+E^{2}-2 U_{k} E \cos \theta}{R^{2}+(\omega L)^{2}}} \\
\phi=\gamma-\operatorname{tg}^{-1}\left[\sin \theta /\left(\cos \theta-E / U_{k}\right)\right]
\end{array}\right.
\end{gathered}
$$

where $\gamma=\operatorname{tg}^{-1}(\omega \mathrm{L} / \mathrm{R})$. Suppose all solution of (6) is

$$
\begin{gathered}
i_{k}=A_{k} e^{-t / \tau}+I \sin \left(\alpha_{k}-\phi\right) \\
i_{d}=\sum_{k=1}^{3} d_{k} i_{k}=\sum_{k=1}^{3}\left[\frac{1}{2}+\frac{m}{2} \sin \left(\alpha_{k}+\theta\right)\right] \cdot\left[A_{k} e^{-\tau / t}+I \sin \left(\alpha_{k}-\phi\right)\right]
\end{gathered}
$$

Suppose $\mathrm{i}_{\mathrm{k}}(0)=0$, we can get

$$
A_{k}=I \sin \left[\phi+(k-1) 120^{\circ}\right] \quad(k=1,2,3)
$$

After simplifing (11), we can obtain

$$
i_{d}=\frac{3 m}{4} I\left[\cos (\theta+\varphi)-e^{-\tau / t} \cos (\omega t+\theta+\varphi)\right.
$$

The inverter output circuit of this paper does not contain a boost transformer, so the equivalent voltage of AC side is very close to the output voltage of the inverter $U_{k}$

$$
E=\rho U_{k}=\rho\left(m u_{k} / 2\right)
$$


AC back electromotive force(EMF) amplitude factor is expressed as $\rho$. Thus it can be obtained that input current $i_{d}$ and resistance function of inverter DC side $R_{d}$ are

$$
\begin{aligned}
& i_{d}=\frac{3 m^{2} u_{d}}{8} \sqrt{\frac{1+\rho^{2}-2 \rho \cos \theta}{R^{2}+(\omega L)^{2}}}\left[\cos (\theta+\varphi)-e^{-\tau / t} \cos (\omega t \theta+\varphi)\right] \\
& R_{d}=\frac{u_{d}}{i_{d}}=\frac{8}{3 m^{2}} \sqrt{\frac{R^{2}+(\omega L)^{2}}{1+\rho^{2}-2 \rho \cos \theta}} \frac{1}{\cos (\theta+\varphi)-e^{-\tau / t} \cos (\omega t+\varphi)}
\end{aligned}
$$

and $\mathrm{e}_{\mathrm{L}}$ is

$$
e_{L}=\left[1-\frac{3 m^{2} R}{8} \sqrt{\frac{1+\rho^{2}-2 \rho \cos \theta}{R^{2}+(\omega L)^{2}}} \cos (\theta+\varphi)\right] u_{d}
$$

As is shown in Figure 6, modulation coefficient of inverter and time constant of transient component can be represented as $\mathrm{m}$ and $\tau(\tau=\mathrm{L} / \mathrm{R})$ [8]. Then PV cell is regarded as a form of voltage source and an internal resistance in series. DC-DC converter and inverter along with circuit after it are simplified as equivalent source and resistance in series. In summary, equivalent circuit model of twostage three-phase grid-connected PV system is shown as followed.

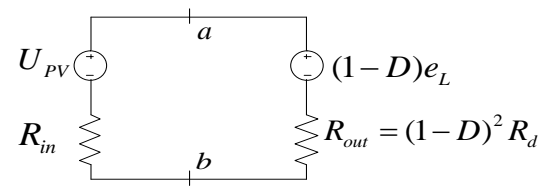

Figure 7. Equivalent circuit of two-stage three-phase grid-connected PV system

\section{MPPT theory based on method of impedance module}

In Figure 5, without the presence of (1-D) $\mathrm{e}_{\mathrm{L}}$, it can be regarded as off-grid PV systems. According to method of impedance module, it is by adjusting duty cycle of DC-DC that equivalent resistance $\mathrm{R}_{\text {out }}$ equals to internal resistance $R_{\text {in }}$ achieving maximum power point tracking; considering the existence of (1-D) $\mathrm{e}_{\mathrm{L}}$ in Figure 7, it can be seen as grid-connected PV generation system, source power conveyed to the port ab is:

$$
P_{a b}=\left(\frac{U_{P V}-(1-D) e_{L}}{R_{i n}+(1-D)^{2} R_{d}}\right) e_{L}+\left(\frac{U_{P V}-(1-D) e_{L}}{R_{i n}+(1-D)^{2} R_{d}}\right)^{2}(1-D)^{2} R_{d}
$$

When transmission power is maximum, resistance $R_{\text {in }}$ is not equal to equivalent resistance $R_{\text {out }}$. By adjusting duty cycle $\mathrm{D}$, partial derivative of $\mathrm{P}_{\mathrm{ab}}$ to Rout equals to zero. After simplifying, the maximum power transmission condition is

$$
R_{\text {in }}=\frac{U_{P V}}{U_{P V}-2(1-D) e_{L}}(1-D)^{2} R_{d}
$$

As long as equivalent resistance $R_{\text {out }}$ and internal resistance $R_{\text {in }}$ match, it will obtain maximum power. Its theoretical basis is from maximum power transfer theorem, so there is unity with method of impedance module. Controls of two-stage grid-connected inverter are generally classified into DC-DC and DC-AC part. Among them, DC-DC control part is responsible for control of Boost circuit, including the MPPT algorithm, voltage regulating device of PV array and DC input current regulator. $\mathrm{PV}$ array voltage command is given from MPPT algorithm, PV array voltage regulator according to 
voltage command provides a DC input current instruction, DC input current regulator according to current instruction gives a switch signal and control action of main circuit.

The MPPT theory mentioned in this paper using inverter DC side equivalent model, maximum power transfer theorem and method of impedance module, regards PV power generation system as research object. Let equivalent resistance Rout match internal resistance Rin to track maximum power point by modulating duty cycle of DC-DC converter.

\section{Simulation}

In order to verify the MPPT based on impedance module in this paper, simulation of two-stage threephase grid-connected PV system whose generation capacity is $100 \mathrm{~kW}$ in standard condition $\left(1000 \mathrm{~W} / \mathrm{m}^{2}\right.$ and 25 degrees Celsius) is carried out in the environment of Matlab/Simulink. Set initial light intensity for $1100 \mathrm{~W} / \mathrm{m}^{2}$ and adjust duty cycle to meet maximum power transfer condition proposed in this paper, and system will be stable in the maximum power point.

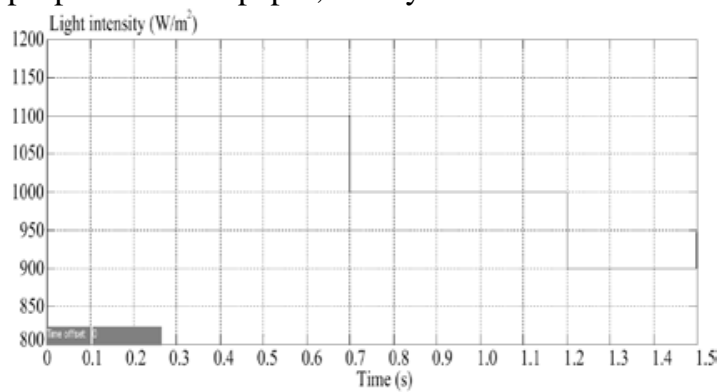

(a) Light intensity

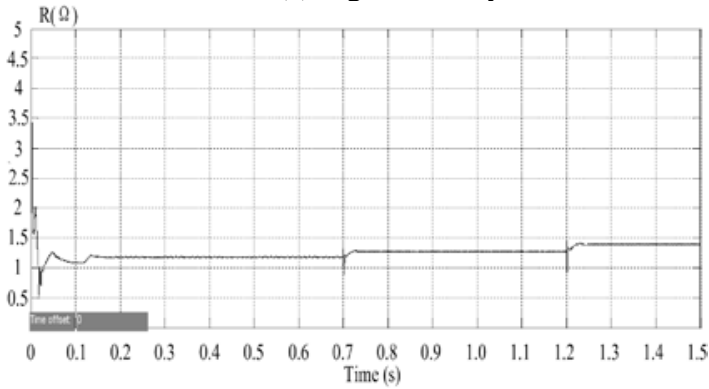

(c) Internal resistance

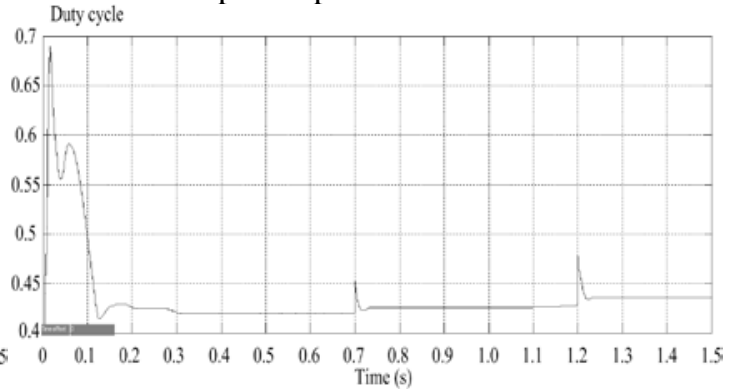

(b) Duty cycle

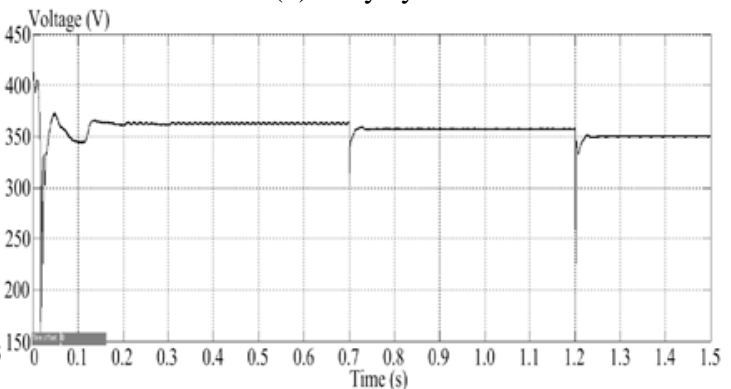

(d) Output voltage of PV array

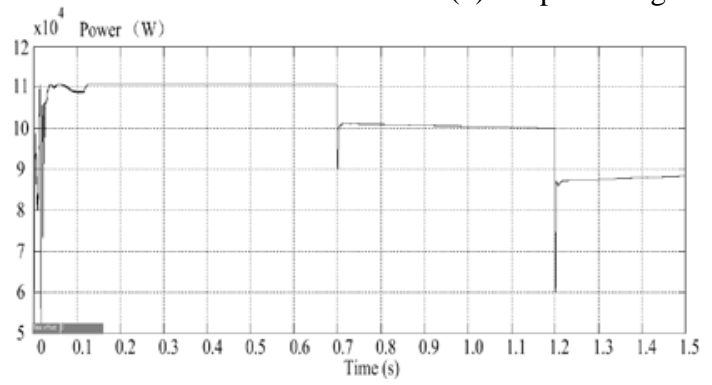

(e) Power obtained from PV array

Figure 8. Results of simulation

Then light intensity is suddenly adjusted to $1000 \mathrm{~W} / \mathrm{m}^{2}$ at the 0.7 seconds, voltage of PV array varies from $360 \mathrm{~V}$ to $355 \mathrm{~V}$ and output power drops to $100 \mathrm{~kW}$ from $110 \mathrm{~kW}$, with internal resistance rising to $1.35 \Omega$ from $1.25 \Omega$ correspondingly. Duty cycle rises to 0.425 from 0.42 . When 1.2 seconds, light intensity is adjusted to $900 \mathrm{~W} / \mathrm{m}^{2}$. The voltage and output power of PV array decrease to $350 \mathrm{~V}$ 
and $80 \mathrm{~kW}$. Internal resistance increases to $1.85 \Omega$. To track the maximum power point of present light intensity, duty cycle is adjusted to meet the maximum power transfer condition again.

\section{Conclusion}

In this paper, approximate simplified equivalent model of inverter DC side is deduced by using SSA model and a new idea of obtaining maximum power is proposed, according to impedance module analysis method that based on the maximum power transfer theorem. Theoretical analysis and simulation results show feasibility of model and idea. To be noted that, due to quantitative Volt Ampere relationship of DC side and equivalent model are complex, research and analysis of equivalent model of DC-side and in this paper is not deep enough, so I hope to get criticism and correction.

\section{Acknowledgment}

This work is supported by Jinzhou City Power Supply Company State Grid Liaoning Electric Power Co. Ltd.

\section{References}

1. L B Wu, ZH M Zhao, J ZH Liu et al,Research on the stability of MPPT strategy applied in singlestage grid-connected photovoltaic system. Proceedings of the CSEE, 26, 73-77 (2006)

2. SH. K. Wei, J. Lei, EN. M. Tan et al, Study on maximum power point tracking control techniques in PV system, Journal of Electronic Measurement and Instrument, vol.25, 490-494 (2011)

3. M. G. Villalva, J. R. Gazoli, E. R. Filho, Comprehensive approach to modeling and simulation of photovoltaic arrays, IEEE Transaction on Power Electronics, vol. 24, 1198-1208 (2009)

4. Z. Liu, The impedance analyses of heavy load node in voltage stability studies, Proceedings of the CSEE, vol.20, 35-39 (2000)

5. B. C. Lu, J. L. Wang, W. G. Guan, P. J. Jiang and L. Y. Sun, A new method to establish the comprehensive model of grid-connected photovoltaic generating electricity system, ICIC Express Letters(EI), vol.4, 1347-1352 (2013)

6. E. Rogers, Understanding Boost Power Stages in Switch mode Power Supplies, TI Literature Number SLUA061, (1999)

7. Z. A. Wang,J. Huang, Power Electronic Technology (China Machine Press, Beijing, 2007)

8. J. S. Zhang, L. Zhang, Research on the DC-side equivalent model of PWM, Proceedings of the CSEE, vol. 27, 103-107 (2007) 